\title{
LETTER
}

\section{Recruitment maneuver after apnea test or continuous positive airway pressure apnea test?}

\author{
Guillaume Lacroix*, Erwan d'Aranda, Jean Cotte, Pierre Esnault, Pierre-Emmanuel Romanat and Philippe Goutorbe \\ See related research by Paries et al., http://ccforum.com/content/16/4/R116
}

We read with interest the study by Marie Paries and collaborators [1]. Many potential lung transplants are lost because of hypoxemia after apnea test. The authors evaluated the positive effect of a single recruitment maneuver (RM) after the apnea test with encouraging effect. In light of the study from Mascia and collaborators [2], we think that the RM will not be necessary if the apnea test is performed with continuous positive airway pressure (CPAP; with positive pressure applied at the level of the positive end expiratory pressure used for ventilation). Using this method for the apnea test, Mascia and collaborators obtained a better $\mathrm{PaO}_{2} / \mathrm{FiO}_{2}$ ratio (the ratio of arterial oxygen tension to fractional inspired oxygen) after the CPAP apnea maneuver compared to the classical apnea maneuver but without the hemodynamic risk.

\section{Authors' response}

Armelle Nicolas-Robin and Marie Paries

We thank Dr Lacroix and colleagues for their interest in our study and we appreciate the opportunity to respond. We wish to remind that the aim of our study [1] was not to compare the $\mathrm{PaO}_{2} / \mathrm{FiO}_{2}$ ratio after apnea tests performed by disconnecting or not the patient from the ventilator. It was to show that hypoxemia after disconnection from the ventilator may be prevented by a single RM applied just after reconnection. Dr Lacroix theorizes that a RM is not useful if the apnea test is performed without disconnection in the CPAP mode. This hypothesis has not been validated, even by Mascia and colleagues [2], who showed that a global lung protective strategy (including no disconnection plus RMs) improved the $\mathrm{PaO}_{2} / \mathrm{FiO}_{2}$ ratio, compared with the conventional strategy (including disconnection with no RM). To our knowledge, the only prevention by the non-disconnection in the CPAP mode has not been evaluated. Our study demonstrated the interest of RM in the case of an apnea test performed by disconnecting the patient from the ventilator. This result is all the more useful because an apnea test performed without disconnection in the CPAP mode is not possible with all ventilators, especially those that do not allow inhibition of the apnea ventilation security mode in case of prolonged apnea.
Competing interests

The authors declare that they have no competing interests.

\section{Abbreviations}

CPAP, continuous positive airway pressure; $\mathrm{FiO}_{2}$, fractional inspired oxygen; $\mathrm{PaO}_{2}$, arterial oxygen tension; $\mathrm{RM}$, recruitment maneuver.

Published: 31 August 2012

\section{References}

1. Paries M, Boccheciampe N, Raux M, Riou B, Langeron O, Nicolas-Robin A: Benefit of a single recruitment maneuver after an apnea test for the diagnosis of brain death. Crit Care 2012, 16:R116.

2. Mascia L, Pasero D, Slutsky AS, Arguis MJ, Berardino M, Grasso S, Munari M, Boifava S, Cornara G, Della Corte F, Vivaldi N, Malacarne P, Del Gaudio P, Livigni S, Zavala E, Filippini C, L. Martin E, Donadio PP, Mastromauro I, Ranieri VM: Effect of a lung protective strategy for organ donors on eligibility and availability of lungs for transplantation. JAMA 2010, 304:2620-2627.
*Correspondence: gllacroix@aol.com

Department of Anesthesiology and Intensive Care, Teaching military hospital Sainte Anne, Boulevard Sainte Anne; BP 20545; 83041 Cedex 09 Toulon, France doi:10.1186/cc11453

Cite this article as: Lacroix, et al:: Recruitment maneuver after apnea test or continuous positive airway pressure apnea test? Critical Care 2012, 16:445. 